\title{
DO BERÇO AO TÚMULO: FAMÍLIAS E CARTÓRIOS NO PARANÁ ${ }^{1}$
}

\author{
Vanderlei Hermes Machado ${ }^{2}$
}

- Enviado em 20/01/2016

- Aprovado em 21/03/2016

A pesquisa intitulada "Do berço ao túmulo: Família e Cartórios no Paraná", se insere na abrangência de pesquisas na área da Sociologia, e se encontra diretamente relacionada a diversidade das relações sociais em uma sociedade. Neste contexto, tal proposta investigativa visa desvendar um fenômeno produzido através das relações sociais que envolvem múltiplos aspectos, dentre eles poderíamos citar relações de poder baseadas no parentesco, na economia e na dinâmica política paranaense.

Há 980 cartórios paranaenses oficialmente registrados no Conselho Nacional de Justiça. Esta serventia extrajudicial, conhecida popularmente pela expressão genérica "cartório", se insere numa vasta gama de instrumentos sociais que visa principalmente à regulação da sociedade, ao passo que dele necessitamos desde o nascimento até a morte. É através do cartório, pela atividade de registradores e tabeliães, que somos apresentados à sociedade, à vida coletiva, nos tornamos cidadãos de fato e de direito. Existimos socialmente através da certidão de nascimento, elaborada através da atividade do Registrador Civil das Pessoas Naturais, responsável também pela publicidade e prova do nome e do estado da pessoa natural, como sua nacionalidade, idade, sexo, capacidade, parentesco e situação conjugal, da mesma forma, atesta a etapa final das pessoas, o falecimento, através da certidão de óbito. Temos no cartório de Registro de Imóveis, a tentativa de garantia de legalidade de todo contrato imobiliário, na medida em que suscita a proteção e a

\footnotetext{
${ }^{1}$ Pesquisa de doutorado em andamento sob a orientação do Professor Doutor Ricardo Costa de Oliveira no Programa de Pós-graduação em Sociologia da UFPR.

${ }^{2}$ Graduado em Sociologia pela Universidade Federal do Paraná. Mestrado em Sociologia pela Universidade Federal do Paraná. Endereço eletrônico: vanderleihermes@yahoo.com.br
} 
regularidade dos direitos reais sobre quaisquer transações envolvendo imóveis. O Registro de Imóveis procura contemplar uma importante função social relativa à regularização fundiária, uma vez que possibilitaria as pessoas de baixo poder aquisitivo o acesso à propriedade e sua regularização legal. No Cartório de Notas ou Tabelião de Notas, temos a função de intermediar as relações comerciais entre as pessoas físicas - a pessoa natural, isto é, todo indivíduo (homem ou mulher), desde seu nascimento até a sua morte - e da mesma maneira entre as pessoas jurídicas representadas por uma entidade abstrata, com existência e responsabilidade jurídicas, tais como, uma associação, empresa, companhia, legalmente autorizadas -, procurando garantir a segurança dos negócios. A cargo do Cartório de Protestos de Títulos a verificação da garantia de cumprimento contratual, em caso de inadimplência e/ou descumprimento da obrigação originada em títulos ou quaisquer outros documentos de dívida, sendo dada a oportunidade ao devedor de pagar ou discutir judicialmente a validade e origem do título ou documento que comprove este fato. Além de conferir cidadania, os cartórios também participam da vida política dos indivíduos, através do Cartório eleitoral. Poderíamos perceber que definir e delimitar este objeto de estudo, requer algumas considerações para sua explanação. A princípio, a instituição conhecida no Brasil como "Cartório", em termos legais, teria como célula - mater seu principal agente, o Tabelião de Notas ou Notário, cuja origem remonta ao nosso primeiro reinado, datado de 1822. Por ocasião da convocação da Assembléia Constituinte por D. Pedro I, visando dotar o país de uma Carta Magna, surgiu a Lei de 20 de outubro de 1823 prescrevendo que se vigorasse no novo Império as Ordenações do Reino de Portugal, ditas “Ordenações Filipinas”. Através delas, Leis, Regimentos, Alvarás, Decretos e Resoluções promulgadas pelos reis de Portugal, valiam também para o Brasil, enquanto não surgisse um novo Código para o país. A palavra Tabelião, deriva de tabula, ou seja, a tábua coberta de cera em que eram inscritos contratos, testamentos, e outros atos jurídicos em Roma. Após a promulgação do Código Filipino em Portugal, somente subsistiram os Tabeliães territoriais ou privativos de localidades cujo provimento pertencia ao poder real como um direito de soberania, o qual concedia a este a autoridade de atestar "fé pública", que legitimava os atos realizados em sua presença, e com o seu aval. Ao Tabelião de Notas, era imputada a responsabilidade pela elaboração de escrituras de contratos privados das mais diversas naturezas, como de compra, venda ou troca de bens móveis e imóveis, testamentos, inventários, entre outros. As Ordenações também mencionavam a categoria de Tabelião do Judicial, que possuía a atribuição de auxiliar, na forma de escrivão, o Juiz de Direito em suas sentenças judiciais, podendo também realizar o inventário de menores e órfãos, caso não houvesse Escrivão de Órfãos para assim proceder. Neste contexto, as Ordenações Filipinas estabeleciam que em qualquer cidade, vila ou 
lugar, onde houvesse um cartório, o Tabelião de Notas ali deveria estar de manhã e à tarde, para a elaboração de escrituras entre partes interessadas. Tais escrituras deveriam ser guardadas em um registro de notas pelo resto da vida do Tabelião e após seu falecimento, obrigava-se aos herdeiros à entrega do mesmo ao seu sucessor, que por sua vez deveria manter sua guarda, durante um período de 40 anos. Era essencial neste processo que o Tabelião reconhecesse as partes envolvidas ou suas testemunhas, em quaisquer negociações por ele presenciada. A forma de elaboração da escritura obedeceria a um rígido formato, sendo imprescindível a citação do dia, mês e ano em que estava sendo lavrada, contendo local, partes envolvidas e a marca de um selo que a autenticasse e legitimasse perante terceiros. Ficava proibida a atuação simultânea de parentes consanguíneos, bem como os adquiridos através de matrimônio em um cartório, que viessem a exercer o mesmo ofício de Tabelião. Eram proibidos também de exercerem cargos de Juiz de Paz no município, e de Vereador nas Câmaras Municipais, onde perante as quais prestavam juramento por escrito de seus ofícios. Obrigavam-se a viver e morar continuadamente na cidade, vila ou lugar, onde estivessem atuando como Tabeliães, sob pena de perderem seus ofícios. Algumas atribuições eram comuns ao Tabelião de Notas e ao Judicial, como a observância em relação ao parentesco e local de atuação, entretanto, outras eram de competência exclusiva deste último, como a obrigatoriedade de servir ao Juiz do local em sua residência, durante três horas pela manhã e à tarde. Caso houvesse mais de um Juiz na localidade, cada um teria de ter seu próprio Tabelião, regulados por um Distribuidor de tarefas. Serviriam como intermediários entre as querelas recebidas da população e o Juiz, a quem teriam de entregar uma cópia dos autos elaborados e assinados por ele e outra ao Tabelião de Notas. Segundo estas Ordenações, ao criar-se uma Vila, concomitantemente havia a necessidade da criação de uma "casa deputada", que servisse de sede para o ofício de Tabelião. O cartório surge juntamente com as cidades e poderíamos considerá-lo uma importante condição para a existência das mesmas.

Deste período até o advento da Constituição de 1988, guardando as devidas proporções e momentos legislativos sobre os cartórios no Brasil, poderíamos afirmar que de uma forma geral, seus titulares eram escolhidos e nomeados pelo poder executivo (na pessoa de Presidentes de Províncias, Interventores e posteriormente Governadores de Estado), sendo prática comum a substituição do Tabelião que deixasse o cargo, por um escrivão mais antigo na função, geralmente alguém da própria família daquele que estaria sendo substituído, dando a impressão de que este era um cargo hereditário. Desde a Constituição Federal de 1988, ingressar nesta atividade passou a depender de concurso público, através de processo seletivo incluindo provas teóricas, práticas e títulos. A análise sociológica em torno do objeto de pesquisa representado pelos cartórios se faz necessária, a partir do momento em que sua importância social necessita ser investigada 
cientificamente. Recentemente este tema assumiu uma posição de destaque na mídia brasileira, como exemplifica a polêmica levantada pelo Projeto de Emenda Constitucional número 471 de 2005 (PEC 471/05), de autoria do deputado federal João Campos (PSDB-GO). O referido projeto, de acordo com notícia veiculada no site Congresso em Foco, intitulada "Câmara prepara trem da alegria para cartórios", apresentava uma proposta de efetivação de cinco (5) mil responsáveis por cartórios no Brasil que assumiriam o cargo por hereditariedade, como donos vitalícios de uma fonte de renda que poderia chegar até dois (2) milhões de reais por mês. Neste sentido, o relatório do Conselho Nacional de Justiça (CNJ) de Julho de 2010, apontou quatrocentos e vinte e seis (426) cartórios em situação irregular no Paraná (destes, 27 em Curitiba), ou seja, com sua titularidade declarada vaga e passível de serem submetidos a concurso público Outro dado relevante neste contexto, fornecido pela matéria intitulada "O Jeitinho paranaense de regular cartórios", publicada no site do Jornal Gazeta do Povo em 03 de outubro de 2010, informa que devido à criação de leis estaduais possuidoras de vícios constitucionais, se fez possível à perpetuação de famílias no comando de cartórios rentáveis e diversas permutas ilegais (quando dois titulares trocam um com o outro uma serventia). Segundo o relatório do Conselho Nacional de Justiça (CNJ), das 14,9 mil serventias brasileiras analisadas, o conselho divulgou a arrecadação de apenas dez, todas no Paraná. Elas seriam um exemplo do que os ministros consideraram uma verdadeira "venda do ponto" por titulares que estavam prestes a se aposentar e realizaram permuta com um familiar, o qual havia passado por um concurso, mas para assumir um cartório do interior, bem menos rentável. Assim, a “perpetuação das famílias" em cartórios rentáveis, assinala a mesma matéria, consta no julgamento de 127 cartórios brasileiros, quase todos no Paraná, sendo que em outros estados a menção seria feita apenas em nove ocasiões: Minas Gerais (três), Rio de Janeiro, Rio Grande do Sul, Ceará, Piauí, Rondônia e Tocantins (um em cada).

Investigar os cartórios em termos de sua composição funcional relacionada a estruturas de parentesco, e suas ligações econômicas e políticas, constitui-se um esforço de pesquisa bastante extenso, uma vez que são raras as produções acadêmicas sobre esta instituição, contando com poucas fontes de informações. Se faz necessário a construção dos dados, levando em consideração uma metodologia de trabalho que possa abranger uma abordagem teórico-empírica. Assim, em termos teóricos, a realização de um apurado levantamento e classificação de documentos tais como jornais, revistas, bibliografias e quaisquer publicações que se encontrem na esfera do tema se mostram de essencial relevância. Em termos geográficos, faz-se necessário a identificação dos 20 maiores municípios do Paraná, localizando seus os cartórios e suas respectivas datas de fundação e quadros funcionais. Um instrumento que auxiliaria muito nesse sentido seria o Sistema de Controle 
de Comarcas do Tribunal de Justiça do Paraná, o qual nos fornece a configuração do quadro de funcionários de todos os cartórios do estado, muitas vezes desde a época de suas fundações. Outros relevantes instrumentos de pesquisa podem ser encontrados na economia política e na história econômica, justamente por proporcionarem a realização de uma investigação das condições materiais, permitindo uma tentativa de estabelecer relações entre a economia e o conjunto da totalidade social. Neste âmbito, a utilização de estudos de caráter genealógico também se apresenta como sendo relevante, na medida em que a genealogia permitiria uma análise temporal do objeto a ser estudado. A contribuição da genealogia residiria principalmente no fato de fornecer informações acerca da gênese e dos processos constitutivos dos grupos familiares a serem investigados em questão, traçando a trajetória dos mesmos no decorrer do tempo. No que concerne à parte empírica, interpretando-a como sendo possuidora de características que privilegiam realidades mais imediatas, a utilização de seus instrumentais se faz necessário mais especificamente na coleta de dados, através da aplicação de questionários e na realização de entrevistas. De acordo com estas afirmações, ambiciona-se uma conjunção entre um quadro de referências teóricas e um quadro de natureza mais empírica, visando à construção de uma pesquisa na confluência entre esses dois esforços metodológicos.

Analisar a configuração da instituição social representada pelos cartórios, numa perspectiva histórico-social, é a principal proposta desta pesquisa. Podemos perceber que o tema envolvendo relações de parentesco é polêmico, e em relação aos cartórios no Paraná, o mesmo deve ser investigado de uma forma científica, procurando identificar o fenômeno nesta instituição, a qual nos acompanha do nascimento ao túmulo. Dados da ANOREG - PR (Associação dos Notários e Registradores do Paraná), nos mostram que o Paraná apresentaria em 2015, aproximadamente 1007 (mil e sete) cartórios e em face desta importante instituição, que regula a vida de todos os cidadãos em seus mais variados aspectos, constituindo também relevante fonte de documentação históricosocial. Nosso objetivo principal se concentra na identificação de uma possível relação de parentesco nos seus quadros funcionais, delimitando a pesquisa aos 20 maiores municípios deste estado. Como delimitação temporal, a pesquisa concentra-se em dois importantes momentos na legislação notarial: os períodos anteriores e posteriores a Constituição de 1988. Como objetivos periféricos, procura também identificar a lógica de funcionamento desta instituição, no que tange a contratação de seus recursos humanos e também como se desenvolvem suas atividades, procurando ir além de suas determinações jurídicas, mas sim, buscando suas determinações sociológicas e também políticas. 